\title{
Highly Selective Oxidation of Ethyl Lactate to Ethyl Pyruvate Catalyzed by Mesoporous Vanadia-Titania
}

\author{
Wei Zhang, ${ }^{\dagger}$ Giada Innocenti, ${ }^{\ddagger}, \nabla$ Paula Oulego, ${ }^{\S}$ Vitaly Gitis, ${ }^{\|}$Haihong Wu, ${ }^{\perp \odot}$ Bernd Ensing, ${ }^{*}, \dagger$ \\ Fabrizio Cavani, ${ }^{\ddagger} \nabla$ Gadi Rothenberg, ${ }^{\dagger}$ and N. Raveendran Shiju* ${ }^{*} \dagger \odot$
}

${ }^{\dagger}$ Van 't Hoff Institute for Molecular Sciences, University of Amsterdam, P.O. Box 94157, 1090GD Amsterdam, The Netherlands

${ }^{\ddagger}$ Dipartimento di Chimica Industriale, ALMA MATER STUDIORUM Università di Bologna, Viale Risorgimento 4, 40136 Bologna, Italy

${ }^{\S}$ Department of Chemical and Environmental Engineering, University of Oviedo, C/Julián Clavería, s/n., E-33071, Oviedo, Spain

"Unit of Environmental Engineering, Ben-Gurion University of the Negev, P.O. Box 653, Beer-Sheva 84105, Israel

${ }^{\perp}$ Shanghai Key Laboratory of Green Chemistry and Chemical Processes, Department of Chemistry, East China Normal University, 3663 North Zhongshan Road, Shanghai 200062, People's Republic of China

${ }^{\nabla}$ Consorzio INSTM, UdR di Bologna, Firenze, Italy

\section{Supporting Information}

\begin{abstract}
The direct oxidative dehydrogenation of lactates with molecular oxygen is a "greener" alternative for producing pyruvates. Here we report a one-pot synthesis of mesoporous vanadia-titania (VTN), acting as highly efficient and recyclable catalysts for the conversion of ethyl lactate to ethyl pyruvate. These VTN materials feature high surface areas, large pore volumes, and high densities of isolated vanadium species, which can expose the active sites and facilitate the mass transport. In comparison to homogeneous vanadium complexes and $\mathrm{VO}_{x} / \mathrm{TiO}_{2}$ prepared by impregnation, the meso-VTN catalysts showed superior activity, selectivity, and stability in the aerobic oxidation of ethyl lactate to ethyl pyruvate. We also studied the effect of various vanadium precursors, which revealed that the vanadium-induced phase transition of meso-VTN from anatase to

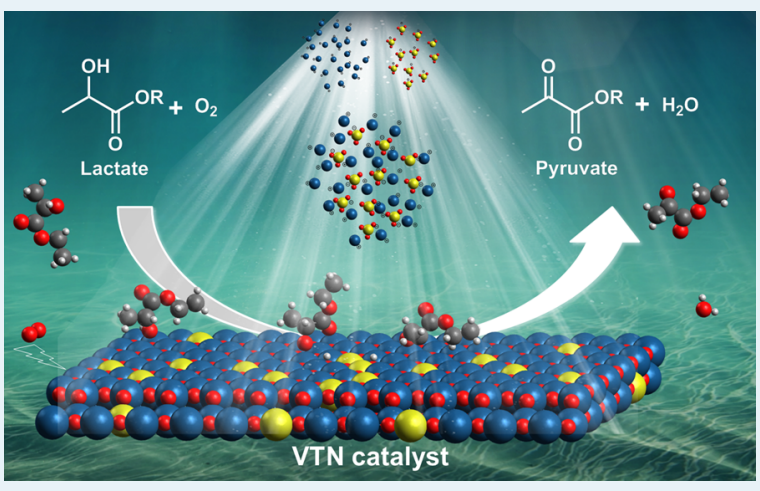
rutile depends strongly on the vanadium precursor. $\mathrm{NH}_{4} \mathrm{VO}_{3}$ was found to be the optimal vanadium precursor, forming more monomeric vanadium species. $\mathrm{V}^{4+}$ as the major valence state was incorporated into the lattice of the $\mathrm{NH}_{4} \mathrm{VO}_{3}$-derived VTN material, yielding more $\mathrm{V}^{4+}-\mathrm{O}-\mathrm{Ti}$ bonds in the anatase-dominant structure. In situ DRIFT spectroscopy and density functional theory calculations show that $\mathrm{V}^{4+}-\mathrm{O}-\mathrm{Ti}$ bonds are responsible for the dissociation of ethyl lactate over VTN catalysts and for further activation of the deprotonation of $\beta$-hydrogen. Molecular oxygen can replenish the surface oxygen to regenerate the $\mathrm{V}^{4+}-\mathrm{O}-\mathrm{Ti}$ bonds.
\end{abstract}

KEYWORDS: biomass conversion, heterogeneous catalysis, mesoporous materials, in situ DRIFTS, DFT

\section{INTRODUCTION}

Lignocellulosic biomass is attracting increased attention as a renewable carbon source for commodity chemicals. ${ }^{1}$ Unlike the case with fuel applications, the high oxygen content and diversity of biomass-derived "platform molecules" make them suitable feedstocks for high-added-value chemicals. ${ }^{2}$ Lactic acid (LA) and lactates are such platform molecules. They can be converted to several commodity chemicals, including acrylic acid, pyruvic acid, lactide, 1,2-propanediol, and acetaldehyde. ${ }^{3}$ The direct catalytic air oxidation of LA is a promising route to pyruvic acid, ${ }^{4}$ a key intermediate in the pharmaceutical, agrochemical, and food additive sectors. ${ }^{5}$ Pyruvic acid occurs naturally as an intermediate product in carbohydrate and protein metabolisms in the body. Since it can be converted to carbohydrates, to fatty acids or energy, or to the amino acid alanine, it is a key intermediate in several metabolic processes. Pyruvic acid salts and esters (pyruvates) are used as dietary supplements. For example, calcium pyruvate is used as a fat burner in the food industry. Pyruvic acid is used as a starting material for the synthesis of pharmaceuticals, such as Ltryptophan and L-tyrosine, and for the synthesis of amino acids such as alanine and phenyl alanine. Its derivatives are also used to produce crop protection agents, cosmetic agents, and flavoring ingredients. Pyruvic acid is also a reagent for regeneration of carbonyl compounds from semicarbazones, phenylhydrazones, and oximes. Currently, pyruvates are still

Received: November 11, 2017

Revised: December 31, 2017

Published: January 9, 2018 
made via the energy-intensive pyrolysis of tartaric acid with stoichiometric $\mathrm{KHSO}_{4}$ as a dehydrating agent. Ideally, this would be replaced by direct oxidative dehydrogenation using molecular oxygen, giving water as the only byproduct. Even though this reaction is thermodynamically feasible, its selectivity is low, because LA is easily overoxidized. ${ }^{6}$

Several groups have studied this oxidation in the vapor and liquid phases. In vapor-phase reactions, various catalysts including iron phosphates and multicomponent mixed oxides were reported. $^{7-9}$ However, such high-temperature routes are energy intensive and can lead to the decomposition of pyruvates via decarbonylation or decarboxylation. ${ }^{10}$ The side reactions can be suppressed in liquid-phase systems, ${ }^{11}$ but the milder conditions typically require noble-metal catalysts for oxygen activation. ${ }^{12}$ Hayashi et al. reported $\mathrm{Pd}-$ metal alloy catalysts on activated carbon for the synthesis of pyruvate in the presence of $\mathrm{NaOH} .{ }^{13}$ Ding and co-workers used bimetallic $\mathrm{Pb}-$ Pt supported on carbon materials for the synthesis of pyruvic acid in good yields, using an excess of $\mathrm{LiOH}$ to adjust the $\mathrm{pH}$ value. ${ }^{14}$ Despite these achievements, it is still essential to develop a simple and cost-effective catalytic system for the oxidation of lactates to pyruvates with oxygen under mild conditions.

Vanadium is an abundant element that is often used as a catalyst in the selective oxidation of light alkanes and alcohols. ${ }^{15}$ Yasukawa et al. studied the oxidation of ethyl lactate to pyruvate over various homogeneous vanadium compounds in a gas-liquid microflow system. ${ }^{16}$ They found that vanadium oxytrichloride $\left(\mathrm{VOCl}_{3}\right)$ gave the highest yield $(31 \%)$ at room temperature, making it 5 times as active as $\mathrm{V}_{2} \mathrm{O}_{5} \cdot{ }^{17}$ Considering catalyst recovery and product purification, solid vanadium catalysts are preferable. ${ }^{18}$ Moreover, the stability of unsupported vanadium compounds is an issue, as they are easily hydrolyzed in the presence of $\mathrm{H}_{2} \mathrm{O}$ produced during the reaction. Previously, we showed that titania is a suitable support for catalyzing the lactate to pyruvate reaction. ${ }^{19}$ In principle, highly dispersed vanadyl species on anatase $\mathrm{TiO}_{2}$ are desired for an efficient oxidation. However, the density of isolated vanadyl species is limited by the titania surface area, and distributing the sites evenly on the surface is problematic at high loadings. In addition, these catalysts are also prone to leaching. ${ }^{20}$ On the basis of our earlier experience with doped mixed oxides for the oxidative dehydrogenation of propane, ${ }^{21}$ we hypothesized that doping vanadium ions into the mesoporous $\mathrm{TiO}_{2}$ lattice would solve these problems. Titania-vanadia hybrids have been made using various methods, including hydrothermal, ${ }^{22,23}$ sol-gel, ${ }^{24}$ electrochemical, ${ }^{25}$ spray pyrolysis, $^{26}$ and coprecipitation. ${ }^{27}$ Gopinath et al. studied wormhole-like mesoporous vanadiumdoped titania in the oxidative dehydrogenation of ethylbenzene to styrene, attributing the high activity to vanadium atoms in the titania lattice. ${ }^{28}$ However, in most of the cases, the vanadium sites embedded in the titania matrix were unavailable for catalysis. Moreover, mesoporous $\mathrm{TiO}_{2}$ typically has a low crystallinity, especially when soft template methods are used, leading to low stability. ${ }^{29,30}$ Thus, we had to find some way to expose the active sites and shorten mass/energy diffusion pathways as well as improve the stability of the catalyst.

Here we report a one-pot synthesis of mesoporous vanadiatitania nanocrystals (meso-VTN) via the coassembly of vanadium and titanium precursors in the presence of an amphiphilic triblock copolymer as a templating agent. These new materials feature a large surface area and a high density of isolated vanadium species. These meso-VTN catalysts out- performed the homogeneous vanadium complexes and classical $\mathrm{VO}_{x}-\mathrm{TiO}_{2}$. We also studied the role of various vanadium precursors in the formation of meso-VTN. Only $\mathrm{NH}_{4} \mathrm{VO}_{3}$, which has the $\mathrm{VO}_{3}{ }^{-}$anion, provided a strong electrostatic interaction with the $\mathrm{Ti}^{4+}$ cations, yielding an anatase-dominant structure. Increasing the vanadium loading also increases the number of active vanadium dopant sites in the titania lattice, which in turn improves activity and selectivity. We also ran in situ DRIFT spectroscopy studies and DFT calculations, which revealed the relation between the structure of the meso-VTN catalyst and its activity in the ethyl lactate oxidation.

\section{RESULTS AND DISCUSSION}

Catalyst Synthesis and Testing. First, the coprecursors ammonium metavanadate $\left(\mathrm{NH}_{4} \mathrm{VO}_{3}\right)$ and titanium isopropoxide were dissolved in acidic ethanol solution, and then the resultant mixture was assembled with F127 template via evaporation-induced self-assembly. Subsequent calcination removed the template (Figure $\mathrm{S} 1$ ), yielding a highly crystalline meso-VTN (denoted as $\mathrm{NH}_{4} \mathrm{VO}_{3} @ \mathrm{VTN}$ ). Three other mesoVTN materials were prepared similarly, starting from different vanadium precursors $\left(\mathrm{VOSO}_{4}, \mathrm{VO}(\mathrm{acac})_{2}\right.$, and $\mathrm{VCl}_{3}$; see the experimental section in the Supporting Information for details).

We then studied the catalytic performance of these mesoVTN materials in the liquid-phase aerobic oxidation of ethyl lactate to ethyl pyruvate (Table 1). In comparison to

Table 1. Oxidative Dehydrogenation of Ethyl Lactate with $\mathrm{O}_{2}$ to Ethyl Pyruvate over Various Catalysts ${ }^{a}$

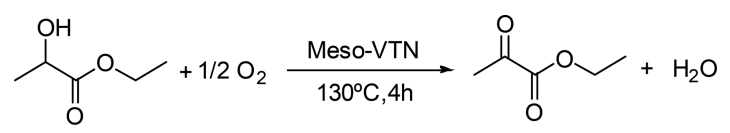

Ethyl lactate

Ethyl pyruvate

\begin{tabular}{|c|c|c|c|c|c|}
\hline entry & catalyst & $\begin{array}{c}\text { conversn } \\
(\%)^{b}\end{array}$ & $\begin{array}{l}\text { selectivity } \\
(\%)\end{array}$ & $\begin{array}{l}\text { yield } \\
(\%)^{b}\end{array}$ & $\begin{array}{l}\text { TOF } \\
\left(\mathrm{h}^{-1}\right)^{c}\end{array}$ \\
\hline 1 & $\mathrm{VCl}_{3}$ & 63.9 & 12.3 & 7.9 & 0.5 \\
\hline 2 & $\mathrm{VOSO}_{4}$ & 63.4 & 32.9 & 20.9 & 1.4 \\
\hline 3 & $\mathrm{VO}(\mathrm{acac})_{2}$ & 79.9 & 64.1 & 51.2 & 5.7 \\
\hline 4 & $\mathrm{NH}_{4} \mathrm{VO}_{3}$ & 64.3 & 72.6 & 46.7 & 2.3 \\
\hline 5 & $\mathrm{~V}_{2} \mathrm{O}_{5}$ & 13.9 & 61.8 & 8.6 & 0.3 \\
\hline $7^{d}$ & $\mathrm{VCl}_{3} @ \mathrm{VTN}$ & 20.8 & 85.1 & 17.7 & 61 \\
\hline $8^{e}$ & VOSO $4 @$ VTN & 25.6 & 71.3 & 18.3 & 86 \\
\hline $9^{f}$ & $\begin{array}{l}\mathrm{VO}(\mathrm{acac})_{2} @ \\
\mathrm{VTN}\end{array}$ & 28.8 & 78.5 & 22.6 & 97 \\
\hline $10^{g}$ & $\mathrm{NH}_{4} \mathrm{VO}_{3} @ \mathrm{VTN}$ & 34.6 & 89.4 & 30.9 & 118 \\
\hline
\end{tabular}

${ }^{a}$ Reaction conditions: amount of all catalysts $50 \mathrm{mg}$, temperature 130 ${ }^{\circ} \mathrm{C}$, $1 \mathrm{~atm}$ of $\mathrm{O}_{2}, 4 \mathrm{~h}$, ethyl lactate $8.5 \mathrm{mmol}(1.0 \mathrm{~g})$, diethyl succinate (solvent) $2 \mathrm{~mL}$. ${ }^{b}$ Determined by GC using biphenyl as an internal standard. ${ }^{c}$ Turnover frequency for ethyl pyruvate formation calculated as moles of ethyl pyruvate per moles of total vanadium per hour. ${ }^{d} \mathrm{VCl}_{3} @ \mathrm{VTN}\left(0.6 \mathrm{wt} \% \mathrm{~V}\right.$, determined by ICP analysis). ${ }^{e} \mathrm{VOSO}_{4} @$

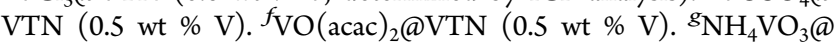
VTN $(0.6$ wt \% V).

homogeneous vanadium complexes, all of the meso-VTN samples showed good catalytic activity and higher turnover frequencies (TOFs). Control reactions showed that the vanadium precursors themselves were active as oxidation catalysts, but not selective. In addition to the intrinsic disadvantages of homogeneous catalysts in catalyst recovery and product purification, the homogeneous vanadium compounds are unstable and are easily hydrolyzed by the water 
byproduct. $^{31,32}$ In contrast, our meso-VTN solid can be reused at least 10 times without losing activity (see recycling experiments below). The highest TOF of $118 \mathrm{~h}^{-1}$ was measured for $\mathrm{NH}_{4} \mathrm{VO}_{3} @ \mathrm{VTN}$.

To understand the high performance of $\mathrm{NH}_{4} \mathrm{VO}_{3} @ \mathrm{VTN}$, we characterized the catalysts. The scanning electron microscopy (SEM) images of the $\mathrm{NH}_{4} \mathrm{VO}_{3} @ \mathrm{VTN}$ samples show highly uniform and nearly spherical morphology in large domains (Figure 1a). The VTN nanoparticles have a rough surface with

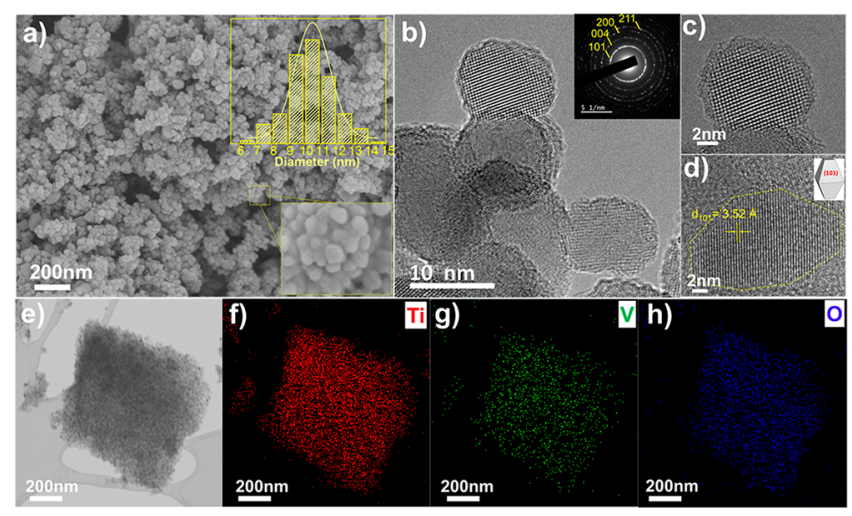

Figure 1. (a) SEM image of $\mathrm{NH}_{4} \mathrm{VO}_{3} @ V T N$. The insets give the particle size distribution (top right) and enlarged SEM image of $\mathrm{NH}_{4} \mathrm{VO}_{3} @ \mathrm{VTN}$ nanospheres (bottom right). (b) Representative TEM image of $\mathrm{NH}_{4} \mathrm{VO}_{3} @ \mathrm{VTN}$ and the corresponding SAED pattern (inset). (c) Magnified HRTEM image of $\mathrm{NH}_{4} \mathrm{VO}_{3} @ V T N$. (d) Crystal plane indexing of $\mathrm{NH}_{4} \mathrm{VO}_{3} @ \mathrm{VTN}$. The inset shows the crystallite shape. (e) STEM image and ( $\mathrm{f}-\mathrm{h})$ corresponding elemental mappings of $\mathrm{Ti}, \mathrm{V}$, and $\mathrm{O}$ in an $\mathrm{NH}_{4} \mathrm{VO}_{3} @ \mathrm{VTN}$ sample.

an average size of $\sim 10 \mathrm{~nm}$ (see inset in Figure 1a). This size agrees well with the size obtained from the high-resolution transmission electron microscopy (HRTEM) studies (Figure 1b,c). HRTEM also confirmed the VTN uniformity. A large number of white dots can be observed by TEM over the entire nanostructure, indicating that the mesoporosity is welldispersed in the VTN framework (see Figure S2 in the Supporting Information). ${ }^{33,34}$ The corresponding selected-area electron diffraction (SAED) pattern confirmed a set of diffraction rings (inset in Figure $1 b$ ), in accordance with the crystalline anatase phase (JCPDS No. 21-1272). Figure 1d also shows the clear lattice fringes with an interplanar distance of $3.52 \AA$, matching well with the (101) planes of the anatase structure. ${ }^{35}$ In addition, the high-angle annular dark-field scanning TEM (HAADF-STEM) images and corresponding elemental mapping further demonstrated the uniform distribution of $\mathrm{Ti}, \mathrm{V}$, and $\mathrm{O}$ atoms in the $\mathrm{NH}_{4} \mathrm{VO}_{3} @ \mathrm{VTN}$ sample (Figure $1 \mathrm{e}-1 \mathrm{~h}$ and Figure S3). ${ }^{36,37}$

Then nitrogen adsorption-desorption experiments for the various meso-VTN samples were performed (Figure 2a). All of the materials showed a typical type IV isotherm with an H1type hysteresis loop, suggesting the presence of mesopores. ${ }^{38}$ Table 2 summarizes the textural parameters. The BET area and pore volume of $\mathrm{NH}_{4} \mathrm{VO}_{3} @ \mathrm{VTN}$ were as high as $112 \mathrm{~m}^{2} \mathrm{~g}^{-1}$ and $0.33 \mathrm{~cm}^{3} \mathrm{~g}^{-1}$, respectively, comparable with those of pristine $\mathrm{TiO}_{2}$. When other vanadium precursors are used, the capillary condensation step becomes less steep and shifts to high relative pressure, indicating a gradual increase in pore size. $^{39}$ This trend agrees well with the results of pore size distribution (Figure 2b), where $\mathrm{NH}_{4} \mathrm{VO}_{3} @ \mathrm{VTN}$ showed a sharp peak indicating uniform pore size, while the peaks of VOSO $4 @$ VTN, VCl 3 @VTN, and VO( acac) $)_{2} @ V T N$ became broad. This difference indicates the key role of vanadium precursors in the formation of meso-VTN. The increase in pore size can be attributed to the different strengths of electrostatic interaction between $\mathrm{Ti}$ and $\mathrm{V}$ precursors during the selfassembly process. ${ }^{40,41}$

$\mathrm{X}$-ray diffraction (XRD) can verify the influence of $\mathrm{V}$ doping on the crystalline structure of meso-VTN. As shown in Figure $3 \mathrm{a}$, no vanadia peaks were detected, suggesting a uniform distribution of vanadium in the VTN crystals, in agreement with the elemental mapping shown in Figure 1. Notably, the (101) diffraction peak shifts slightly toward a higher angle after the introduction of vanadium species (Figure $3 \mathrm{~b}$ ). This implies that the vanadium ions are incorporated in the titania lattice. ${ }^{42}$ For $\mathrm{NH}_{4} \mathrm{VO}_{3} @ \mathrm{VTN}$, the XRD pattern showed the characteristic anatase titania peaks, with a trace amount of rutile. However, with other vanadium compounds as precursors, the intensity of the rutile diffraction peaks increased while the anatase fraction decreased. Notably, $\mathrm{VCl}_{3} @ V T N$ showed a rutile-dominant diffraction pattern. The anatase:rutile ratios, calculated on the basis of the integrated intensities of the anatase (101) peak and rutile (110) peak, ${ }^{43}$ are shown in Table 2. The anatase content in meso-VTN decreases as follows: $\mathrm{NH}_{4} \mathrm{VO}_{3}>\mathrm{VOSO}_{4}>\mathrm{VO}(\mathrm{acac})_{2}>\mathrm{VCl}_{3}$. This confirms that the vanadium-induced phase transition of meso-VTN from anatase to rutile depends strongly on the vanadium precursor. Figure $3 c$ shows the Raman spectra of all V-doped VTN samples. The Raman characterization also upholds the XRD results. All of the samples showed a set of bands at $146\left(\mathrm{E}_{\mathrm{g}}\right)$, $198\left(\mathrm{E}_{\mathrm{g}}\right), 396\left(\mathrm{~B}_{1 \mathrm{~g}}\right), 516\left(\mathrm{~A}_{1 \mathrm{~g}}+\mathrm{B}_{1 \mathrm{~g}}\right)$ and $638\left(\mathrm{E}_{\mathrm{g}}\right) \mathrm{cm}^{-1}$, which are assigned to the fundamental active modes of anatase
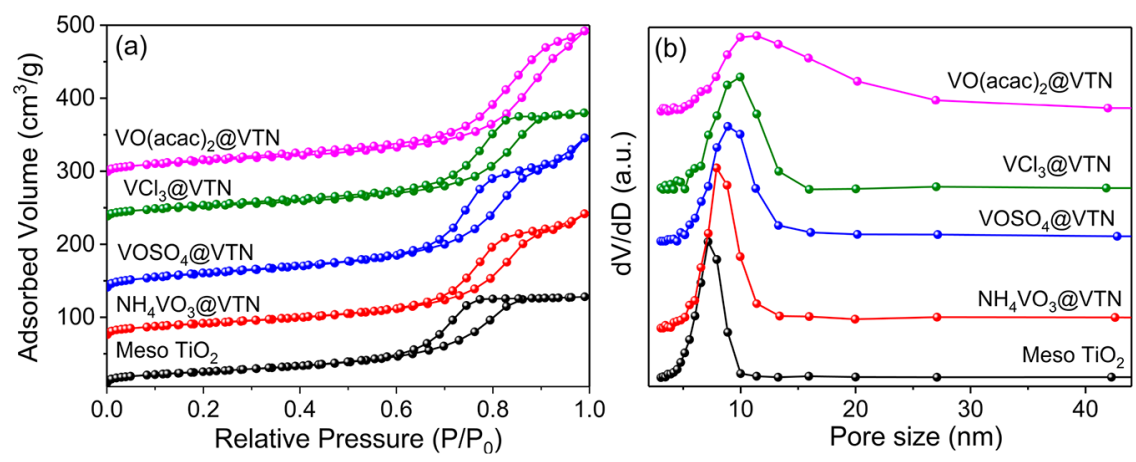

Figure 2. Nitrogen adsorption-desorption isotherms (a) and $\mathrm{BJH}$ pore size distribution curves (b) of pure $\mathrm{TiO}_{2}$ and meso-VTN materials prepared from different $\mathrm{V}$ precursors. 
Table 2. Textural Parameters of Meso-VTN Materials

\begin{tabular}{|c|c|c|c|c|c|}
\hline sample & vanadium loading $(\text { wt } \%)^{a}$ & anatase:rutile $^{b}$ & $S_{\text {BET }}\left(\mathrm{m}^{2} \mathrm{~g}^{-1}\right)^{c}$ & pore volume, $V_{\mathrm{p}}\left(\mathrm{cm}^{3} \mathrm{~g}^{-1}\right)^{c}$ & . \\
\hline mesoporous $\mathrm{TiO}_{2}$ & & $>100: 1$ & 121 & 0.2 & 7.1 \\
\hline $\mathrm{NH}_{4} \mathrm{VO}_{3} @ \mathrm{VTN}$ & 0.59 & $95: 5$ & 112 & 0.33 & 7.9 \\
\hline VOSO $_{4} @ V T N$ & 0.46 & $90: 10$ & 93 & 0.27 & 8.9 \\
\hline VO(acac) $)_{2} @ V T N$ & 0.5 & $81: 19$ & 87 & 0.31 & 10 \\
\hline $\mathrm{VCl}_{3} @ \mathrm{VTN}$ & 0.6 & $41: 59$ & 82 & 0.23 & 8.8 \\
\hline
\end{tabular}

${ }^{a}$ Determined by ICP analysis. ${ }^{b}$ The weight percentage of the rutile phase was calculated using the formula $W_{\mathrm{R}}=1 /\left[1+0.884\left(A_{\mathrm{A}} / A_{\mathrm{R}}\right)\right]$, where $A_{\mathrm{A}}$ and $A_{\mathrm{R}}$ represent the XRD integrated intensities of anatase (101) and rutile (110) diffraction peaks. ${ }^{c}$ Calculated on the basis of $\mathrm{N}_{2}$ sorption at $77 \mathrm{~K}$. ${ }^{d}$ Calculated from the BJH method.
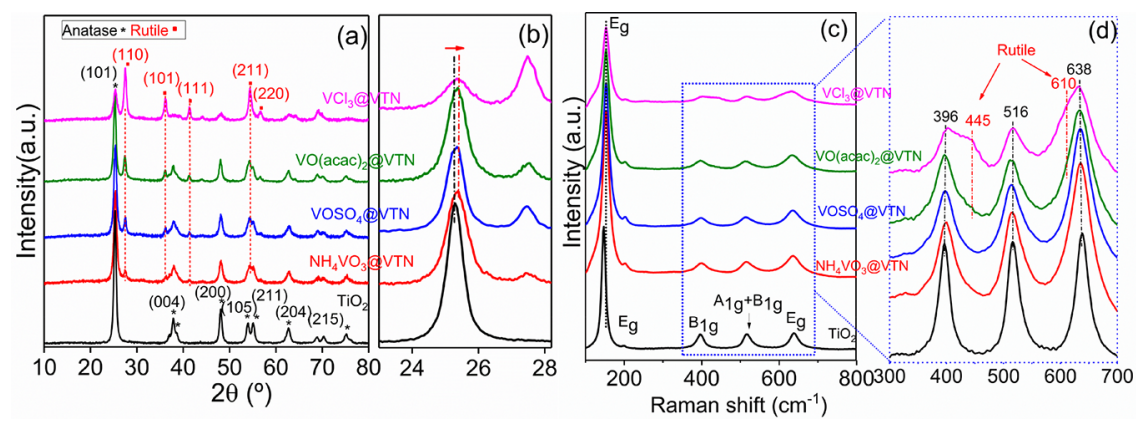

Figure 3. X-ray diffraction patterns (a, b) and Raman spectra (c, d) of blank- $\mathrm{TiO}_{2}$ and $\mathrm{VTN}$ materials prepared from different vanadium precursors. Due to the low loadings, $\mathrm{VO}_{x}$ species were not observed.

$\mathrm{TiO}_{2}{ }^{28,44}$ No typical Raman peaks of $\mathrm{VO}_{x}$ species were detected, indicating the absence of crystalline vanadium oxides, also supporting the complete doping of vanadium into the anatase lattice. ${ }^{45}$ In addition, all of the peaks of VTN samples became asymmetric in comparison to pure $\mathrm{TiO}_{2}$ (Figure 3d). This holds especially for $\mathrm{VO}(\mathrm{acac})_{2}$ and $\mathrm{VCl}_{3} @ \mathrm{VTN}$, where two weak bands at 445 and $610 \mathrm{~cm}^{-1}$ were observed, which can be assigned to the rutile $\mathrm{TiO}_{2}$ features. ${ }^{43}$ Among those vanadium precursors, only $\mathrm{NH}_{4} \mathrm{VO}_{3}$ has the $\mathrm{VO}_{3}{ }^{-}$anion, which could provide a strong electrostatic interaction with the $\mathrm{Ti}^{4+}$ cations, showing a more anatase dominant structure. Note that both anatase and rutile titania are made up of $\mathrm{TiO}_{6}$ octahedra in tetragonal configurations. ${ }^{46}$ The structural difference between them is caused by the stacking arrangement of these $\mathrm{TiO}_{6}$ units. The metastable anatase structure consists of edge-sharing $\mathrm{TiO}_{6}$ octahedra in zigzag stacking, while the stable rutile consists of both corner and edge-sharing $\mathrm{TiO}_{6}$ in the linear stacking. ${ }^{47,48}$ Titanium oligomers can interact with vanadium precursors via electrostatic interaction during the self-assembly process. ${ }^{49}$ The substitution of the lattice Ti by $\mathrm{V}$ ions distorts the anatase structure, thus promoting the transformation from anatase to rutile.

Temperature-programmed reduction studies showed that $\mathrm{NH}_{4} \mathrm{VO}_{3}$ forms monomeric $\mathrm{VO}_{4}$ units (Figure 4). After vanadium was introduced into the titania lattice, the maximum hydrogen consumption $\left(T_{\max }\right)$ shifted to lower temperature, in comparison with pure $\mathrm{TiO}_{2}$ and $\mathrm{V}_{2} \mathrm{O}_{5}$. Generally, the nature of the $\mathrm{VO}_{x}$ species affects the reducibility of $\mathrm{V}$-doped $\mathrm{TiO}_{2}$. Monomeric $\mathrm{VO}_{4}$ species are more easily reduced. ${ }^{50}$ Among the VTN samples, $\mathrm{NH}_{4} \mathrm{VO}_{3} @ V T N$ showed the lowest $T_{\max }$ value, suggesting that $\mathrm{NH}_{4} \mathrm{VO}_{3} @ \mathrm{VTN}$ forms more monomeric vanadium species. This may reflect the strong electrostatic interaction between $\mathrm{VO}_{3}{ }^{-}$and the $\mathrm{Ti}^{4+}$ precursors. We conclude that $\mathrm{NH}_{4} \mathrm{VO}_{3}$ is the best precursor, as it provides a strong electrostatic interaction with the $\mathrm{Ti}^{4+}$ cations, thereby suppressing the agglomeration of vanadium species (Scheme 1).

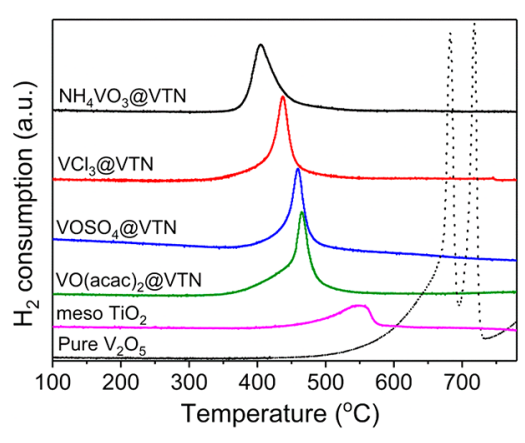

Figure 4. $\mathrm{H}_{2}$-TPR profiles of $\mathrm{TiO}_{2}, \mathrm{~V}_{2} \mathrm{O}_{5}$, and VTN materials with different $\mathrm{V}$ precursors.

Scheme 1. Illustration of the Synthesis Route of $\mathrm{NH}_{4} \mathrm{VO}_{3} @$ VTN via Electrostatic Interaction between the $\mathrm{VO}_{3}{ }^{-}$and the $\mathrm{Ti}^{4+}$ Precursors

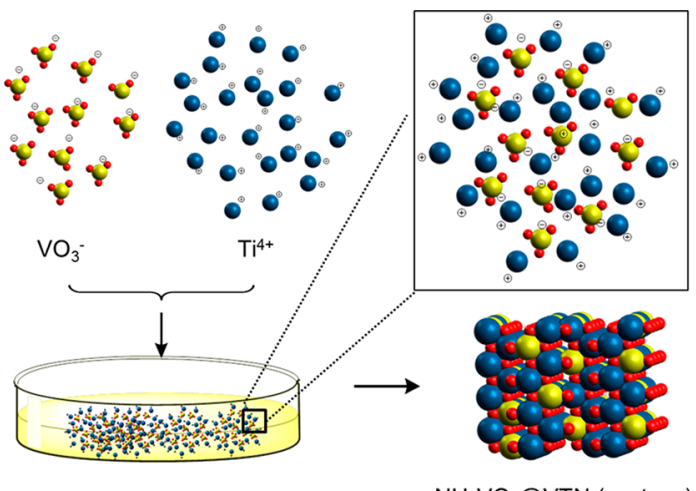

$\mathrm{NH}_{4} \mathrm{VO}_{3} @ \mathrm{VTN}$ (anatase)

Factors Governing Activity and Selectivity. We examined the effect of reaction conditions on the aerobic oxidation of ethyl lactate with dioxygen over the $\mathrm{NH}_{4} \mathrm{VO}_{3} @$ VTN catalyst. As shown in Figure 5, the selectivity of ethyl 


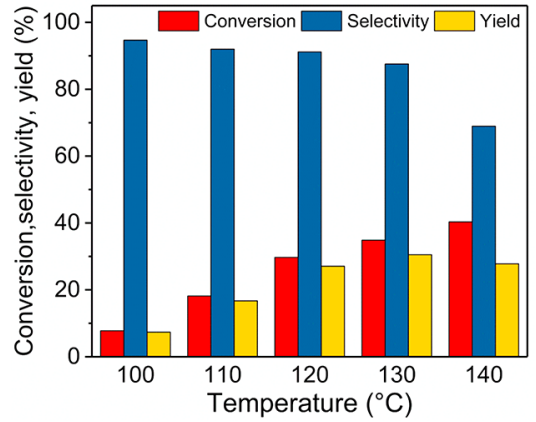

Figure 5. Effect of reaction temperature on the aerobic oxidation of ethyl lactate. Reaction conditions: 0.6\%V-N $\mathrm{NH}_{4} \mathrm{VO}_{3} @ \mathrm{VTN} 50 \mathrm{mg}, 1$ atm $\mathrm{O}_{2}, 2 \mathrm{~h}$, ethyl lactate $8.5 \mathrm{mmol}(1.0 \mathrm{~g})$, diethyl succinate (solvent) $2 \mathrm{~mL}$.

pyruvate was high at lower temperatures and decreased gradually with increasing temperature. Ethyl lactate conversion increased with the reaction temperature, with the highest yield to ethyl pyruvate obtained at $130{ }^{\circ} \mathrm{C}$. Increasing the temperature further decreased the yield of ethyl pyruvate. We also plotted the selectivity of major products against ethyl lactate conversion and reaction time over $0.6 \% \mathrm{~V}-\mathrm{NH}_{4} \mathrm{VO}_{3} @$ VTN at optimized temperature. As shown in Figure 6a, the ethyl lactate conversion increased with the reaction time, reaching $70 \%$ after $8 \mathrm{~h}$, with ethyl pyruvate as the main product together with ethanol, pyruvic acid, and some minor byproducts. The ethyl pyruvate selectivity gradually decreased from $91 \%$ to $58 \%$ with the reaction time on stream, as the amounts of both ethanol and pyruvic acid increased to $28 \%$ and $11 \%$, respectively. Several minor byproducts including acetic acid and acetaldehyde were detected at a steady state with a selectivity of $\sim 2 \%$. On the basis of these results, we propose a reaction network for the aerobic oxidation of ethyl lactate, involving oxidative dehydrogenation, hydrolysis, and decarboxylation steps (Figure 6b).

We also studied the effect of vanadium loading on the catalytic activity by modifying the $\mathrm{NH}_{4} \mathrm{VO}_{3}$ precursor concentration for a series of $\mathrm{NH}_{4} \mathrm{VO}_{3} @ \mathrm{VTN}$ materials. These catalysts are denoted as $x \mathrm{~V}-\mathrm{NH}_{4} \mathrm{VO}_{3} @ \mathrm{VTN}$, where $x$ represents the weight ratio (wt \%) of vanadium. The corresponding porosity analysis and textural parameters are given in Figure S4 and Table S1 in the Supporting Information. Figure $7 \mathrm{a}$ shows the selectivity-conversion curves of these
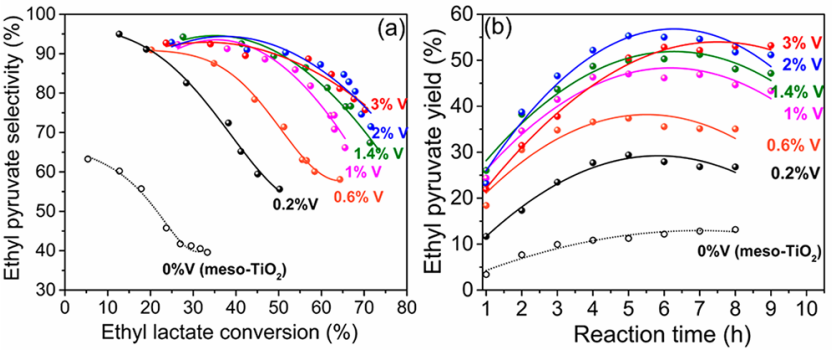

Figure 7. Selectivity to ethyl pyruvate plotted against conversion (a) of $\mathrm{NH}_{4} \mathrm{VO}_{3} @ \mathrm{VTN}$ on varying the vanadium loading from 0 to $3 \mathrm{wt} \%$ and (b) the corresponding time-resolved yield profile of ethyl pyruvate. Reaction conditions: catalyst $50 \mathrm{mg}, 1 \mathrm{~atm} \mathrm{O}_{2}, 130{ }^{\circ} \mathrm{C}$, ethyl lactate $8.5 \mathrm{mmol}(1.0 \mathrm{~g})$, diethyl succinate (solvent) $2 \mathrm{~mL}$.

$\mathrm{NH}_{4} \mathrm{VO}_{3} @ \mathrm{VTN}$ catalysts. Pure meso- $\mathrm{TiO}_{2}(0 \% \mathrm{~V})$ showed some conversion, but selectivity to pyruvate was low. We think that the basic $\mathrm{OH}$ groups on the $\mathrm{TiO}_{2}$ surface can hydrolyze lactate and pyruvate to ethanol and lactic/pyruvic acid. When vanadium was introduced in $\mathrm{TiO}_{2}$, the resulting VTN catalysts showed high ethyl pyruvate selectivity, reaching 95\% at low ethyl lactate conversion. At higher ethyl lactate conversions, the selectivity of ethyl pyruvate tended to increase with an increase in the $\mathrm{V}$ loading (from $0.2 \%$ to $2 \% \mathrm{~V}$ ). ${ }^{9}$ This indicates that vanadium acts as the active site in lactate-to-pyruvate reaction, and at higher vanadium loadings, the competing hydrolysis is suppressed. To check this, we ran control experiments on the aerobic oxidation of ethyl lactate over $0.2 \mathrm{~V} \%-\mathrm{NH}_{4} \mathrm{VO}_{3} @ \mathrm{VTN}$, using molecular sieves $3 \AA$ (MS-3A) as a dehydrating agent (Figure S5). Addition of MS-3A gave a much higher selectivity of $80 \%$ to ethyl pyruvate (at $51.6 \%$ conversion), in comparison to $56 \%$ (at $50.2 \%$ conversion) in the absence of MS-3A (Figure $\mathrm{S} 5 \mathrm{a})$. Without the dehydrating agent, the amount of byproducts was higher: e.g., a selectivity to ethanol of $22 \%$ instead of $10 \%$ (Figure S5b). When the $\mathrm{V}$ loading was increased to $3 \%$, the difference between $2 \%$ and $3 \%$ almost leveled up. To better understand this trend, we plotted the ethyl pyruvate yield

(b)
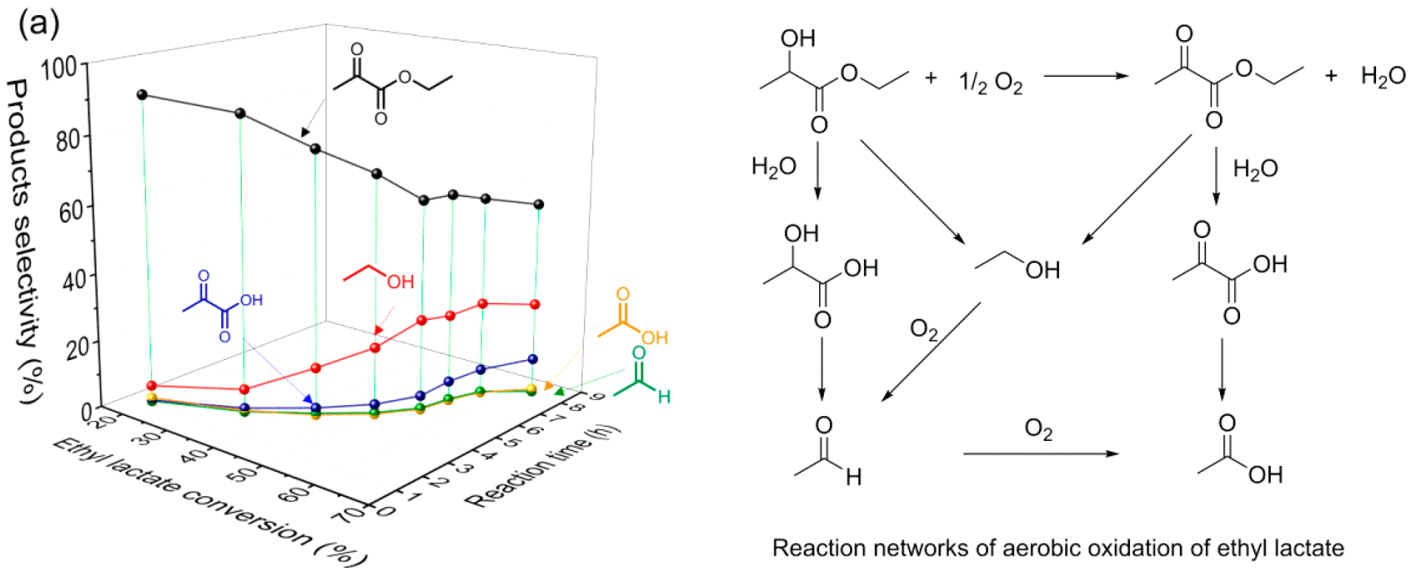

Reaction networks of aerobic oxidation of ethyl lactate

Figure 6. (a) Plots of product selectivity against ethyl lactate conversion and reaction time. Reaction conditions: 0.6\% $-\mathrm{NH}_{4} \mathrm{VO}_{3} @ \mathrm{VTN} 50 \mathrm{mg}, 1$ atm $\mathrm{O}_{2}$, temperature $130{ }^{\circ} \mathrm{C}$, ethyl lactate $8.5 \mathrm{mmol}(1.0 \mathrm{~g}$ ), diethyl succinate (solvent) $2 \mathrm{~mL}$. (b) Proposed reaction pathway for the aerobic oxidation of ethyl lactate. 
against reaction time (Figure $7 \mathrm{~b}$ ), which confirmed that $2 \% \mathrm{~V}$ $\mathrm{NH}_{4} \mathrm{VO}_{3} @ V T N$ gives the highest yield. Indeed, the crystalline

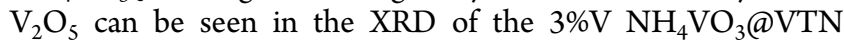
sample, suggesting that some of the vanadium is aggregated as $\mathrm{V}_{2} \mathrm{O}_{5}$ (see Figure $\mathrm{S} 6$ in the Supporting Information). Thus, increasing the vanadium loading also increases the number of active vanadium dopant sites in the titania lattice, which in turn results in improved overall activity and selectivity.

Further insight into the reaction can be gained by analyzing structure-activity relationships. Interestingly, we found that the TOF of $\mathrm{NH}_{4} \mathrm{VO}_{3} @ \mathrm{VTN}$ was inversely proportional to the vanadium loading (Figure 8a), showing a close correlation with

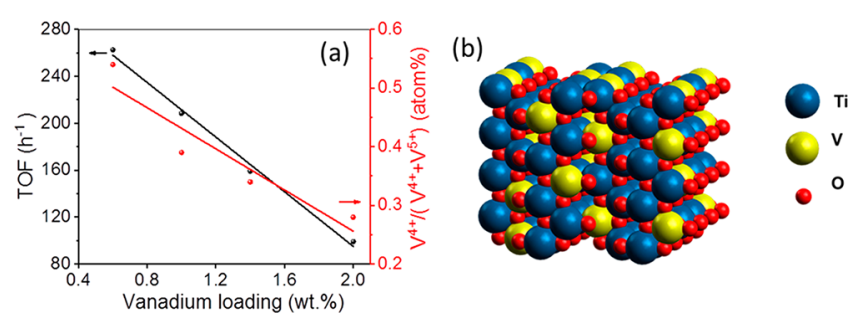

Figure 8. (a) Relationship among turnover frequency (TOF) for ethyl pyruvate formation, $\mathrm{V}^{4+} /\left(\mathrm{V}^{4+}+\mathrm{V}^{5+}\right)$ (atom \%), and loading of vanadium catalysts. Reaction conditions: $\mathrm{NH}_{4} \mathrm{VO}_{3} @ \mathrm{VTN} 50 \mathrm{mg}, 1$ atm $\mathrm{O}_{2}, 1 \mathrm{~h}$, ethyl lactate $8.5 \mathrm{mmol}(1.0 \mathrm{~g})$, diethyl succinate (solvent) $2 \mathrm{~mL}$. (b) Model of Anataste VTN. Atom colors: Ti, blue; O, red; V, yellow.

the ratio $\mathrm{V}^{4+} /\left(\mathrm{V}^{4+}+\mathrm{V}^{5+}\right)$ (derived from the $\mathrm{V} 2 \mathrm{p}$ spectrum in Table 3). In particular, the amounts of exposed $\mathrm{V}^{4+}$ ions are correlated with catalytic performance. The similar ionic radii of $\mathrm{Ti}^{4+}(0.61 \AA)$ and $\mathrm{V}^{4+}(0.58 \AA)$ enable the doping of the latter into the titania lattice $\left(\mathrm{V}^{5+}\right.$ is much smaller, $\left.0.54 \AA\right) .{ }^{45}$ To understand this behavior at the atomic level, we built a simple model of anatase titania (Figure $8 \mathrm{~b}$ ) and performed density functional theory (DFT) calculations of the substitution of $\mathrm{V}^{4+}$ and $\mathrm{V}^{5+}$ for $\mathrm{Ti}^{4+}$ in the anatase lattice (a more detailed description of the simulations is provided in the Supporting Information). We found that exchanging the surface $\mathrm{Ti}$ with $\mathrm{V}^{4+}$ on anatase $\mathrm{TiO}_{2}$ corresponds to a lower energy in comparison to that of $\mathrm{V}^{5+}$, in line with previous reports.

$\mathrm{X}$-ray photoelectron spectroscopy (XPS) measurements show that the Ti 2p peaks of $\mathrm{NH}_{4} \mathrm{VO}_{3} @ V T N$ containing $0.6 \% \mathrm{~V}$ and $1 \% \mathrm{~V}$ are asymmetric, in comparison with pure $\mathrm{TiO}_{2}$ (Figure 9A, a-c). This indicates the presence of two types of $\mathrm{Ti}$ on the surface. The binding energy corresponding to $\mathrm{Ti}^{4+}\left(\mathrm{Ti} 2 \mathrm{p}_{1 / 2}, 464.8 \mathrm{eV} ; \mathrm{Ti} 2 \mathrm{p}_{3 / 2}, 459.1 \mathrm{eV}\right)$ is shifted toward higher values. These results imply that $\mathrm{Ti}$ is replaced with $\mathrm{V}$, decreasing the electron charge density of $\mathrm{Ti}^{4+} .{ }^{52}$ This means that the neighboring lattice $\mathrm{Ti}$ (denoted as $\mathrm{Ti}_{(\mathrm{V})}$ ) of the vanadium dopant gives a high binding energy. For comparison, we prepared $0.6 \% \mathrm{VO}_{x} / \mathrm{TiO}_{2}$ using impregnation, where the $\mathrm{Ti}_{(\mathrm{V})}$ peak was not detected in XPS spectra (Figure S7). This further confirmed the substitution of lattice Ti by vanadium. As the vanadium loading increases, the deconvoluted peaks corresponding to $\mathrm{Ti}_{(\mathrm{V})}$ gradually disappear (Figure $9 \mathrm{~A}, \mathrm{~d}$ and e). When more vanadium is incorporated in the $\mathrm{TiO}_{2}$ lattice, isolated $\mathrm{V}^{4+}$ will be gradually converted to polymerized $\mathrm{VO}_{x}$, thus lowering the fraction of $\mathrm{Ti}_{(\mathrm{V})}{ }^{53}$ This agrees also with the decrease in the ratio $\mathrm{V}^{4+} /\left(\mathrm{V}^{4+}+\mathrm{V}^{5+}\right)$ (Figure $9 \mathrm{~B}$ and Table 3 ). When the $\mathrm{V}$ loading is increased to $3 \%$, the peaks of crystalline $\mathrm{V}_{2} \mathrm{O}_{5}$ can be seen in the XRD pattern (Figure S6). As shown in Figure 9C, the spectra of $\mathrm{O} 1 \mathrm{~s}$ in $\mathrm{NH}_{4} \mathrm{VO}_{3} @ \mathrm{VTN}$ can be deconvoluted into three peaks: the peak at $530.3 \mathrm{eV}$ was ascribed to the $\mathrm{O}^{2-}$ lattice oxygen $\left(\mathrm{O}_{\mathrm{I}}\right)$, and the peaks at $\sim 531.6$ and $\sim 532.3 \mathrm{eV}$ are ascribed to $\mathrm{O}_{2}{ }^{2-}$ and $\mathrm{O}^{-}$surface chemisorbed oxygen (labeled as $\mathrm{O}_{\mathrm{II}}$ and $\mathrm{O}_{\mathrm{III}}$ ). ${ }^{54}$ The $\mathrm{O}_{\mathrm{II}}$ oxygens, which are located at the surface defects, are more active and therefore more easily reduced. ${ }^{55,56}$ As vanadium ions with different valences replace $\mathrm{Ti}^{4+}$ ions in the lattice, the charge imbalance generates structural defects and additional oxygen vacancies. ${ }^{57,58}$ This increases the number of mobile $\mathrm{O}_{\text {II }}$ species. ${ }^{59}$ In our case, the $\mathrm{V}^{4+} /\left(\mathrm{V}^{4+}+\mathrm{V}^{5+}\right)$ ratio decreased from 0.54 to 0.28 when $\mathrm{V}$ loading is increased, and the $\mathrm{O}_{\mathrm{II}} /\left(\mathrm{O}_{\mathrm{I}}+\mathrm{O}_{\mathrm{II}}\right.$ $+\mathrm{O}_{\text {III }}$ ) fraction decreased simultaneously.

Leaching of active species into the solution is a known problem in heterogeneous catalysis. To rule out the possibility of vanadium leaching, we ran a hot filtration experiment (Figure S8). ${ }^{60}$ When the $\mathrm{NH}_{4} \mathrm{VO}_{3} @ \mathrm{VTN}$ catalyst was filtered from the reaction mixture after $3 \mathrm{~h}$, no further ethyl lactate conversion was observed. Moreover, the vanadium content of the filtrate was below the detection limit of ICP-AES analysis. For comparison, we prepared vanadia supported on titania with an identical surface vanadium content using impregnation (herein $\mathrm{VO}_{x} / \mathrm{TiO}_{2}$; the vanadium content on the surface was determined by XPS). Mesoporous anatase $\mathrm{TiO}_{2}$ was impregnated with aqueous solutions of $\mathrm{NH}_{4} \mathrm{VO}_{3}$ and oxalic acid, followed by drying and calcining for $4 \mathrm{~h}$ at $500{ }^{\circ} \mathrm{C}$. Control experiments showed that the filtrate of $\mathrm{VO}_{x} / \mathrm{TiO}_{2}$ was still active in ethyl lactate oxidation (Figure S9), indicating that $\mathrm{V}$ species do leach into solution in the case of impregnation. We also determined the recyclability of $\mathrm{NH}_{4} \mathrm{VO}_{3} @ \mathrm{VTN}$. In each run, the catalyst was separated by simple centrifugation and then dispersed in water under ultrasonication for $1 \mathrm{~h}$. As shown in Figure 10, the $\mathrm{NH}_{4} \mathrm{VO}_{3} @ \mathrm{VTN}$ could be reused 10 times without significant loss of activity. The XRD and TEM analysis confirmed that the meso structure and anatase/rutile ratio were well preserved after recycling (Figure S10).

Mechanistic Considerations. To study the reaction mechanism of lactate to pyruvate on the $\mathrm{NH}_{3} \mathrm{VO}_{4} @ \mathrm{VTN}$ surface, we did in situ DRIFTS studies. Figure 11 shows the results for the aerobic oxidation of ethyl lactate over $0.2 \% \mathrm{~V}$ $\mathrm{NH}_{3} \mathrm{VO}_{4} @ V T N$ at $130{ }^{\circ} \mathrm{C}$ at different reaction times. Typical vibrational bands of ethyl lactate on $\mathrm{NH}_{3} \mathrm{VO}_{4} @ V T N$ were observed after ethyl lactate adsorption. The positive bands at 2987, 2943, and $2885 \mathrm{~cm}^{-1}$ were ascribed to $\nu_{\text {as }}\left(\mathrm{CH}_{3}\right)$,

Table 3. Surface Atom Ratios of $\mathrm{NH}_{4} \mathrm{VO}_{3} @ V T N$ Calculated from XPS Analysis

\begin{tabular}{|c|c|c|c|c|c|c|c|}
\hline sample & $\mathrm{V}^{5+}($ atom $\%)$ & $\mathrm{V}^{4+}($ atom $\%)$ & $\mathrm{O}_{\mathrm{I}}($ atom \%) & $\mathrm{O}_{\mathrm{II}}($ atom \%) & $\mathrm{O}_{\text {III }}($ atom \%) & $\mathrm{V}^{4+} /\left(\mathrm{V}^{4+}+\mathrm{V}^{5+}\right)$ & $\mathrm{O}_{\mathrm{II}} /\left(\mathrm{O}_{\mathrm{I}}+\mathrm{O}_{\mathrm{II}}+\mathrm{O}_{\mathrm{III}}\right)$ \\
\hline meso- $\mathrm{TiO}_{2}$ & & & 52.7 & 6 & 2.2 & & 0.10 \\
\hline 0.6\%V-NH $\mathrm{NO}_{3} @ \mathrm{VTN}$ & 1.13 & 1.32 & 38.05 & 17.1 & 6.83 & 0.54 & 0.28 \\
\hline $1 \% \mathrm{~V}-\mathrm{NH}_{4} \mathrm{VO}_{3} @ \mathrm{VTN}$ & 1.77 & 1.12 & 33.43 & 15.14 & 7.51 & 0.39 & 0.27 \\
\hline $1.4 \% \mathrm{~V}-\mathrm{NH}_{4} \mathrm{VO}_{3} @ \mathrm{VTN}$ & 2.52 & 1.35 & 39.52 & 14.37 & 4.08 & 0.34 & 0.25 \\
\hline $2 \% \mathrm{~V}-\mathrm{NH}_{4} \mathrm{VO}_{3} @ \mathrm{VTN}$ & 4.07 & 1.57 & 45.38 & 13.32 & 2.48 & 0.28 & 0.22 \\
\hline
\end{tabular}



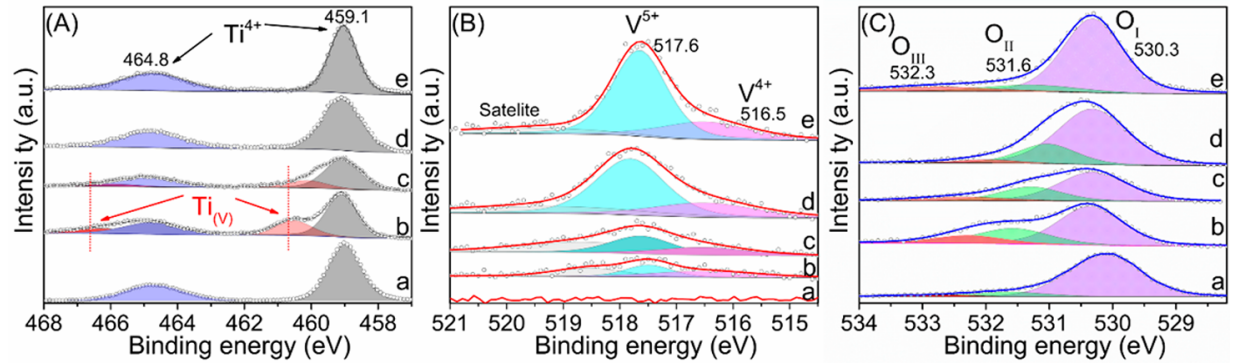

Figure 9. XPS studies showing high-resolution Ti $2 p$ spectra (A), high-resolution V $2 p$ spectra (B), and high-resolution $\mathrm{O} 1 \mathrm{~s}$ spectra (C) of the $\mathrm{NH}_{4} \mathrm{VO}_{3} @ \mathrm{VTN}$ with different V loadings: (a) $0 \% \mathrm{~V}$ (meso- $\mathrm{TiO}_{2}$ ); (b) $0.6 \% \mathrm{~V}$; (c) $1 \% \mathrm{~V}$; (d) $1.4 \% \mathrm{~V}$; (e) $2 \% \mathrm{~V}$.

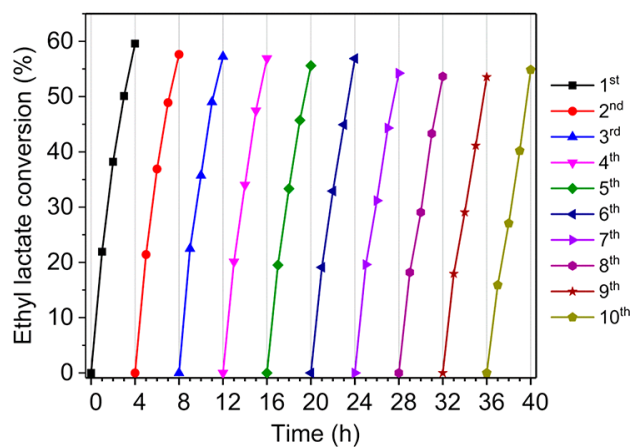

Figure 10. Kinetic plots of recycling tests of $\mathrm{NH}_{3} \mathrm{VO}_{4} @ \mathrm{VTN}$ in the oxidation of ethyl lactate to ethyl pyruvate. Reaction conditions: 100 mg catalyst, $130{ }^{\circ} \mathrm{C}, 1 \mathrm{~atm} \mathrm{O}_{2}, 4 \mathrm{~h}$, ethyl lactate $8.5 \mathrm{mmol}(1 \mathrm{~g})$, diethyl succinate (solvent) $2 \mathrm{~mL}$.

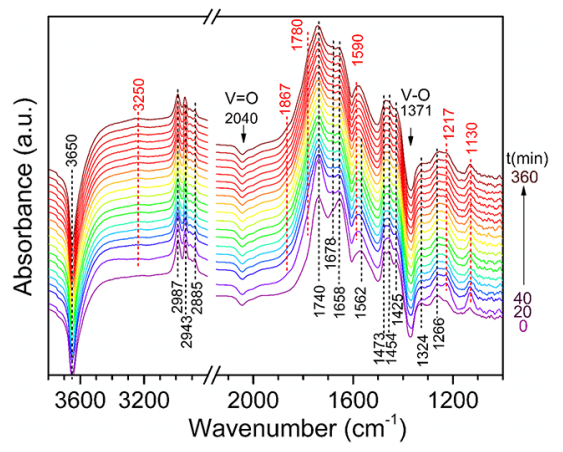

Figure 11. In situ DRIFT spectra recorded during aerobic oxidation of ethyl lactate with air over 0.2\%- $\mathrm{NH}_{3} \mathrm{VO}_{4} @ \mathrm{VTN}$ catalyst at different time intervals $(0,20,40, \ldots, 360 \mathrm{~min})$ at $130^{\circ} \mathrm{C}$.

$\nu_{\mathrm{as}}\left(\mathrm{CH}_{2}\right)$, and $\nu_{\mathrm{s}}\left(\mathrm{CH}_{3}\right)$, respectively. ${ }^{61,62}$ The corresponding $\mathrm{C}-\mathrm{H}$ bending vibrations were also detected $\left(\delta\left(\mathrm{CH}_{2}\right) 1473\right.$ $\mathrm{cm}^{-1}, \delta\left(\mathrm{CH}_{3}\right) 1454 \mathrm{~cm}^{-1}$, and $\left.\delta\left(\mathrm{CH}_{3}\right) 1324 \mathrm{~cm}^{-1}\right){ }^{61,63}$ The lactate carboxyl stretching vibrations were observed at 1562 $\mathrm{cm}^{-1}\left(\nu_{\mathrm{s}}(\mathrm{COO})\right)$ and $1425 \mathrm{~cm}^{-1}\left(\nu_{\mathrm{as}}(\mathrm{COO})\right)$, while the peak at $1740 \mathrm{~cm}^{-1}$ belongs to the lactate carbonyl $\nu(\mathrm{C}=\mathrm{O}){ }^{61}$ Two additional peaks appeared at 1678 and $1658 \mathrm{~cm}^{-1}$, probably due to the $\mathrm{C}=\mathrm{O}$ bonds coordinated with the VTN surface. ${ }^{64}$ After 20 min, we observed two new shoulder peaks at 1867 and 1780 $\mathrm{cm}^{-1}$, which are related to the carbonyl stretching of the $\alpha$-keto group of the pyruvate. ${ }^{65}$ The intensity of pyruvate bands increased with the reaction time on stream; meanwhile, $\nu_{\mathrm{s}}(\mathrm{COO})$ at $1562 \mathrm{~cm}^{-1}$ gradually shifted to $1590 \mathrm{~cm}^{-1}$, suggesting the formation of more ethyl pyruvate. Moreover, two weak bands at 1130 and $1217 \mathrm{~cm}^{-1}$ can be ascribed to the hydroxyl-related $\mathrm{C}-\mathrm{O}$ vibrations of ethyl lactate $\left(\nu_{\text {lactate }}(\mathrm{C}-\mathrm{O})\right.$ and $\left.\delta_{\text {lactate }}(\mathrm{C}-\mathrm{O})\right)$, reflecting the $\mathrm{OH}$ deprotonation of ethyl lactate on VTN surface. The signals of $\nu_{\text {lactate }}(\mathrm{C}-\mathrm{O})$ and $\delta_{\text {lactate }}(\mathrm{C}-\mathrm{O})$ reached a maximum in the first $20 \mathrm{~min}$, indicating that the lactate $\mathrm{OH}$ deprotonation plays a key role in this reaction. This is also confirmed by the new broad band at $\sim 3250 \mathrm{~cm}^{-1}$, which indicates the formation of adsorbed water on VTN surface. ${ }^{65}$ Note that the $\mathrm{V}=\mathrm{O}$ overtone band ( $\sim 2040$ $\left.\mathrm{cm}^{-1}\right)^{63}$ is well-preserved during the aerobic oxidation of ethyl lactate, while the $\mathrm{V}-\mathrm{O}$ related bond $\left(\delta\left(\mathrm{V}^{4+}-\mathrm{O}-\mathrm{Ti}\right) \sim 1370\right.$ $\left.\mathrm{cm}^{-1}\right)^{66}$ is diminished in intensity. This indicates that the terminal $\mathrm{V}=\mathrm{O}$ bonds are not involved in the ethyl lactate conversion, confirming the vital role of $\mathrm{V}^{4+}-\mathrm{O}$ related bonds.

To complement the experimental results and the reaction pathways for the oxidative dehydrogenation of ethyl lactate to ethyl pyruvate, we built a periodic model of VTN by replacing lattice $\mathrm{Ti}$ with $\mathrm{V}^{4+}$ in the top layer of the (101) facet of anatase titania. This model was simulated using density functional theory (DFT) calculations as implemented in the $\mathrm{CP} 2 \mathrm{~K}$ package (see the Supporting Information for details). First, we studied the adsorption and dissociation of ethyl lactate (EL) on the VTN surface. Several possible adsorbed forms were considered (see Figure S11). Geometry optimization showed that EL can be stabilized on either surface titanium or vanadium atoms (Figure 12). The hydroxyl oxygen coordinates to surface titanium atoms with a $\mathrm{Ti} \cdots \mathrm{OH}-\mathrm{R}$ distance of $2.085 \AA$, in comparison with a V $\cdots \mathrm{OH}-\mathrm{R}$ distance of $2.126 \AA$. In both cases, the $\mathrm{O}-\mathrm{H}$ bonds were elongated, from $0.974 \AA$ to 1.039 (a)

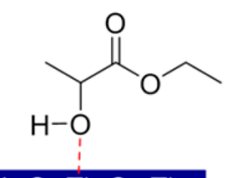

$-\mathrm{V}-\mathrm{O}-\mathrm{Ti}-\mathrm{O}-\mathrm{Ti}-$

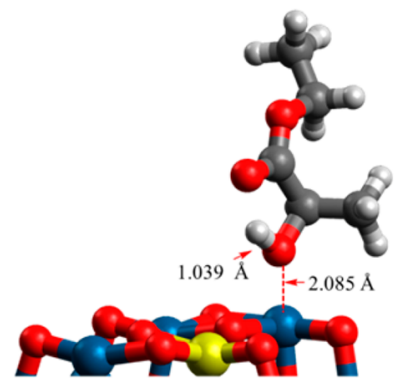

(b)
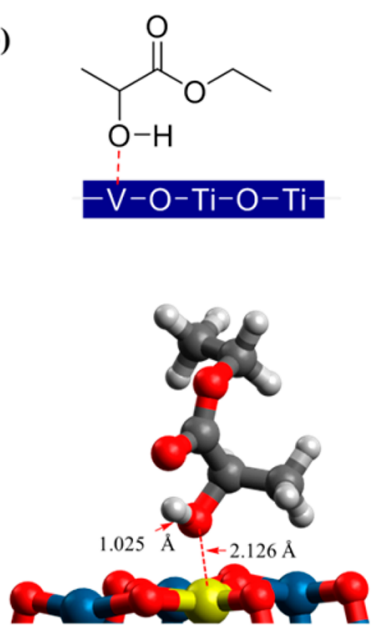

Figure 12. Optimized geometries of two different models for ethyl lactate chemisorption on the VTN (101) surface: (a) Ti-type adsorption geometry, where ethyl lactate interacts with the $\mathrm{Ti}$ atom; (b) V-type adsorption geometry, where ethyl lactate interacts with the $\mathrm{V}$ atom. Atom colors: Ti, blue; O, red; V, yellow. 
and $1.025 \AA$, respectively. The adsorption energy of EL on Ti was higher than that of $\mathrm{EL}$ on $\mathrm{V}$ by $0.73 \mathrm{kcal} / \mathrm{mol}$, in agreement with previous reports. ${ }^{19}$

Then, activation of the hydroxyl group triggers the dissociation of EL via proton transfer to a nearby bridging oxygen atom $\left(\mathrm{O}_{\mathrm{br}}\right)$. To simplify this process, we focused on two types of bridges: $\mathrm{V}^{4+}-\mathrm{O}-\mathrm{Ti}\left(\mathrm{O}_{\mathrm{br}-\mathrm{V}}\right)$ and $\mathrm{Ti}-\mathrm{O}-\mathrm{Ti}\left(\mathrm{O}_{\mathrm{br}-\mathrm{Ti}}\right)$. Figure 13 shows the geometries of two possible intermediates,

(a)
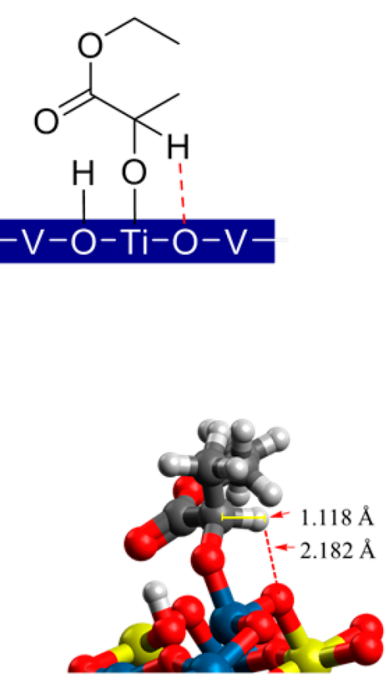

Figure 13. Representative structures of the two intermediates during proton transfer process: (a) hydrogen atom transfer to bridging oxygen atoms in $\mathrm{V}-\mathrm{O}-\mathrm{Ti}$ sites; (b) hydrogen atom transfer to bridging oxygen atoms in $\mathrm{Ti}-\mathrm{O}-\mathrm{Ti}$ sites.

(a) and (b), in this step. In both cases, the protonated EL is bonded to a titanium atom. Yet while in (a) the hydroxyl $\mathrm{H}$ transfers to a nearby $\mathrm{V}^{4+}-\mathrm{O}-\mathrm{Ti}$ site, forming a $\mathrm{H}-\mathrm{O}_{\mathrm{br}-\mathrm{V}}$ bond, in (b) the proton transfers to a $\mathrm{Ti}-\mathrm{O}-\mathrm{Ti}$ to form a $\mathrm{H}-\mathrm{O}_{\mathrm{br}-\mathrm{Ti}}$ bond. The intermediate energies for the formation of (a) and (b) are -75.6 and $-136 \mathrm{kcal} / \mathrm{mol}$, respectively. This suggests that the $\mathrm{V}^{4+}-\mathrm{O}-\mathrm{Ti}$ bonds are responsible for the dissociation of ethyl lactate over VTN catalysts, supporting the experimental result. In addition, the $\beta$-hydrogen of the protonated EL can interact with the $\mathrm{V}^{4+}-\mathrm{O}-\mathrm{Ti}$ oxygen, increasing the $\mathrm{C}-\mathrm{H}_{\beta}$ bond length from 1.099 to $1.118 \AA$.

Therefore, the simulations show us that (i) ethyl lactate adsorbs preferentially on the VTN surface via the coordination of hydroxyl oxygen to titanium, (ii) $\mathrm{V}^{4+}-\mathrm{O}-\mathrm{Ti}$ bonds play a vital role in the dissociation of ethyl lactate, and (iii) the deprotonation of $\beta$-hydrogen is also activated by $\mathrm{V}^{4+}-\mathrm{O}-\mathrm{Ti}$ bonds.

For most oxidative dehydrogenation reactions, the molecular oxygen activation involves either free radical or Mars-van Krevelen pathways. ${ }^{67}$ To determine if any radical species is involved in this reaction, we introduced a number of free radical scavengers to the reaction mixture (BHT, $p$-benzoquinone, and tert-butyl alcohol; see Table S2). These free radical scavengers did not suppress the reaction completely, ruling out the formation of free radical intermediates (i.e., superoxide radical $\mathrm{O}_{2}{ }^{\bullet-}$ ) in the bulk reaction mixture. To further study the role of molecular oxygen, we ran control experiments over $\mathrm{NH}_{4} \mathrm{VO}_{3} @$ VTN, where the molecular oxygen was replaced by nitrogen. The reaction was limited without oxygen. ${ }^{55,56}$ Thus, we can conclude that the aerobic oxidation follows a Mars-van Krevelen mechanism for VTN catalysts, wherein molecular oxygen can replenish the $\mathrm{V}^{4+}-\mathrm{O}-\mathrm{Ti}$ bonds. A trace amount of ethyl lactate was converted to ethyl pyruvate in nitrogen initially, probably due to the oxygen still chemisorbed on the surface of VTN. This anaerobic process of lactate to pyruvate was also observed by in situ DRIFTS experiments at elevated temperatures under a helium atmosphere. The signals for the $\mathrm{V}^{4+}-\mathrm{O}-\mathrm{Ti}$ bonds gradually decreased and shifted to higher wavelengths, accompanied by the formation of the characteristic peaks of pyruvate (Figure S12).

On the basis of the experimental and computational results, we can propose a probable mechanism (Scheme 2). Starting

Scheme 2. Proposed Catalytic Cycle for the Oxidative Dehydrogenation of Ethyl Lactate to Ethyl Pyruvate in the Presence of Meso-VTN

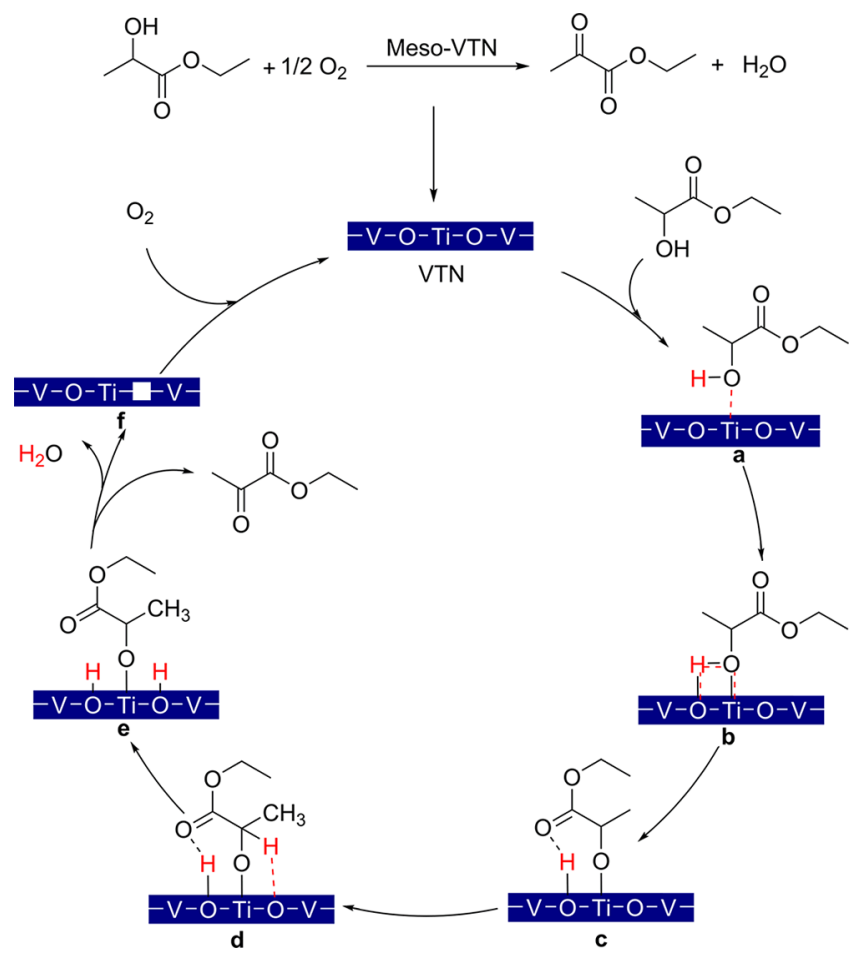

with the pristine catalyst VTN, ethyl lactate adsorbs and then chemisorbs by the coordinated bond to titanium atoms a and further forms the transition state $\mathbf{b}$. Then, the hydroxyl $\mathrm{H}$ atom transfers to near $\mathrm{V}^{4+}-\mathrm{O}-\mathrm{Ti}$ sites, forming the $\mathrm{Ti}^{4+}-\mathrm{O}-$ substrate intermediate and a $\mathrm{V}^{4+}-\mathrm{O}-\mathrm{H}$ bond (c). This is followed by $\beta$-hydrogen activation through an interaction with an adjacent $\mathrm{V}^{4+}-\mathrm{O}-\mathrm{Ti}$ oxygen, giving the five-membered intermediate $\mathbf{d}$. Ethyl pyruvate is then produced by $\beta$-hydrogen elimination, giving water as a byproduct as well as creating an oxygen vacancy $(\mathbf{e}, \mathbf{f})$. Finally, adsorbed oxygen replenishes the oxygen vacancy, regenerating the $\mathrm{V}^{4+}-\mathrm{O}-\mathrm{Ti}$ bonds. In general, structural defects containing lower oxidation state cations are reported to be necessary to activate the oxygen. Here, we anticipate that $\mathrm{V}^{4+}$, because of its lower oxidation state, can activate oxygen better than $\mathrm{V}^{5+}$. This could be also connected with the fact that a linear relationship is observed between TOF and the amount of $\mathrm{V}^{4+}$ in the samples.

\section{CONCLUSIONS}

We developed a one-pot strategy for the controllable synthesis of uniform mesoporous vanadia-titania nanoparticles (VTNs). 
$\mathrm{NH}_{4} \mathrm{VO}_{3}$ is the optimal vanadium precursor, forming primarily monomeric $\mathrm{VO}_{4}$ units, avoiding the agglomeration of polymeric vanadium species as well as the formation of a rutile structure to a great extent. In comparison to homogeneous vanadium compounds and the classical $\mathrm{VO}_{x}-\mathrm{TiO}_{2}$ prepared by impregnation, the meso-VTN catalysts showed superior catalytic activity and selectivity for the ODH of ethyl lactate to ethyl pyruvate. In addition, $\mathrm{V}^{4+}$ as the major valence state was incorporated into the anatase $\mathrm{TiO}_{2}$, which can increase the availability of surface chemisorbed oxygen, resulting in high catalytic activity for aerobic oxidation of ethyl lactate. Hot filtration and recyclability tests confirmed that $\mathrm{NH}_{4} \mathrm{VO}_{3} @ \mathrm{VTN}$ does not leach into solution and can be reused at least 10 times without loss of activity. In situ DRIFTS and DFT simulations show that ethyl lactate adsorbs preferentially on the VTN surface via the coordination of hydroxyl oxygen to titanium. The $\mathrm{V}^{4+}-\mathrm{O}-\mathrm{Ti}$ bonds play a key role in the dissociation of ethyl lactate and further promote the deprotonation of $\beta$ hydrogen. In addition, molecular oxygen can replenish the surface oxygen to regenerate the $\mathrm{V}^{4+}-\mathrm{O}-\mathrm{Ti}$ bonds. Thus, this work provides fundamental insights for developing further simple and cost-effective catalytic systems for highly efficient conversion of biomass derivatives to value-added chemicals under mild conditions.

\section{ASSOCIATED CONTENT}

\section{S Supporting Information}

The Supporting Information is available free of charge on the ACS Publications website at DOI: 10.1021/acscatal.7b03843.

Experimental procedures, computational details, additional characterization data of VTN catalysts including $\mathrm{XRD}$ patterns, nitrogen adsorption-desorption isotherms, SEM/TEM images, EDX spectra, XPS spectra, $\mathrm{H}_{2}$-TPR profiles, in situ DRIFT spectra, and results of hot filtration tests and the effect of addition of freeradical scavengers (PDF)

\section{AUTHOR INFORMATION}

\section{Corresponding Authors}

*E-mail for B.E.: b.ensing@uva.nl.

*E-mail for N.R.S.: n.r.shiju@uva.nl.

\section{ORCID $\odot$}

Wei Zhang: 0000-0003-4506-6583

Haihong Wu: 0000-0001-6266-8290

N. Raveendran Shiju: 0000-0001-7943-5864

Notes

The authors declare no competing financial interest.

\section{ACKNOWLEDGMENTS}

W.Z. thanks the China Scholarship Council for a Ph.D. fellowship. This work is part of the Research Priority Area Sustainable Chemistry of the UvA, http://suschem.uva.nl. P.O. thanks the Spanish Ministry of Economy and Competitiveness (MINECO) (Project CTM2015-63864-R) and European Union (FEDER) for funding. V.G. thanks Holland Research School of Molecular Chemistry for a visiting fellowship.

\section{REFERENCES}

(1) Gallezot, P. Chem. Soc. Rev. 2012, 41, 1538-1558.

(2) Beerthuis, R.; Rothenberg, G.; Shiju, N. R. Green Chem. 2015, 17, $1341-1361$
(3) Dusselier, M.; Van Wouwe, P.; Dewaele, A.; Makshina, E.; Sels, B. F. Energy Environ. Sci. 2013, 6, 1415-1442.

(4) Mäki-Arvela, P.; Simakova, I. L.; Salmi, T.; Murzin, D. Y. Chem. Rev. 2014, 114, 1909-1971.

(5) Xu, P.; Qiu, J.; Gao, C.; Ma, C. J. Biosci. Bioeng. 2008, 105, 169175.

(6) Sousa, S. C. A.; Fernandes, A. C. Coord. Chem. Rev. 2015, 284, 67-92.

(7) Ai, M. Appl. Catal., A 2002, 232, 1-6.

(8) Zhao, X.; Zhang, C.; Xu, C.; Li, H.; Huang, H.; Song, L.; Li, X. Chem. Eng. J. 2016, 296, 217-224.

(9) Liu, K. T.; Huang, X. M.; Pidko, E. A.; Hensen, E. J. M. Green Chem. 2017, 19, 3014-3022.

(10) Lomate, S.; Bonnotte, T.; Paul, S.; Dumeignil, F.; Katryniok, B. J. Mol. Catal. A: Chem. 2013, 377, 123-128.

(11) Sugiyama, S.; Kikumoto, T.; Tanaka, H.; Nakagawa, K.; Sotowa, K.-I.; Maehara, K.; Himeno, Y.; Ninomiya, W. Catal. Lett. 2009, 131, 129-134.

(12) Mallat, T.; Baiker, A. Chem. Rev. 2004, 104, 3037-3058.

(13) Tsujino, T.; Ohigashi, S.; Sugiyama, S.; Kawashiro, K.; Hayashi, H. J. Mol. Catal. 1992, 71, 25-35.

(14) Zhang, C.; Wang, T.; Ding, Y. J. Appl. Catal., A 2017, 533, 5965.

(15) Wachs, I. E. Dalton Trans. 2013, 42, 11762-11769.

(16) Yasukawa, T.; Ninomiya, W.; Ooyachi, K.; Aoki, N.; Mae, K. Chem. Eng. J. 2011, 167, 527-530.

(17) Yasukawa, T.; Ninomiya, W.; Ooyachi, K.; Aoki, N.; Mae, K. Ind. Eng. Chem. Res. 2011, 50, 3858-3863.

(18) Nguyen, H. G. T.; Schweitzer, N. M.; Chang, C.-Y.; Drake, T. L.; So, M. C.; Stair, P. C.; Farha, O. K.; Hupp, J. T.; Nguyen, S. T. ACS Catal. 2014, 4, 2496-2500.

(19) Ramos-Fernandez, E. V.; Geels, N. J.; Shiju, N. R.; Rothenberg, G. Green Chem. 2014, 16, 3358-3363.

(20) Kim, J.; McNamara, N. D.; Hicks, J. C. Appl. Catal., A 2016, $517,141-150$.

(21) Rothenberg, G.; de Graaf, E. A.; Bliek, A. Angew. Chem., Int. Ed. 2003, 42, 3366-3368.

(22) Zamani, S.; Meynen, V.; Hanu, A.-M.; Mertens, M.; Popovici, E.; Van Doorslaer, S.; Cool, P. Phys. Chem. Chem. Phys. 2009, 11, 5823-5832.

(23) Shi, Q.; Li, Y.; Zhan, E.; Ta, N.; Shen, W. CrystEngComm 2015, 17, 3376-3382.

(24) Choi, J.; Shin, C. B.; Park, T.-J.; Suh, D. J. Appl. Catal., A 2006, $311,105-111$.

(25) Long, L.-L.; Zhang, A.-Y.; Yang, J.; Zhang, X.; Yu, H.-Q. ACS Appl. Mater. Interfaces 2014, 6, 16712-16720.

(26) Schimmoeller, B.; Schulz, H.; Ritter, A.; Reitzmann, A.; Kraushaar-Czametzki, B.; Baiker, A.; Pratsinis, S. E. J. Catal. 2008, 256, 74-83.

(27) Ortel, E.; Sokolov, S.; Zielke, C.; Lauermann, I.; Selve, S.; Weh, K.; Paul, B.; Polte, J.; Kraehnert, R. Chem. Mater. 2012, 24, 38283838.

(28) Sivaranjani, K.; Verma, A.; Gopinath, C. S. Green Chem. 2012, 14, 461-471.

(29) Yoshitake, H.; Tatsumi, T. Chem. Mater. 2003, 15, 1695-1702.

(30) Hossain, M. K.; Akhtar, U. S.; Koirala, A. R.; Hwang, I. C.; Yoon, K. B. Catal. Today 2015, 243, 228-234.

(31) Hanson, S. K.; Wu, R.; Silks, L. A. P. Org. Lett. 2011, 13, 19081911.

(32) Bie, Z.; Li, G.; Wang, L.; Lv, Y.; Niu, J.; Gao, S. Tetrahedron Lett. 2016, 57, 4935-4938.

(33) Jun, Y.-S.; Park, J.; Lee, S. U.; Thomas, A.; Hong, W. H.; Stucky, G. D. Angew. Chem., Int. Ed. 2013, 52, 11083-11087.

(34) Yun, D.; Kim, T. Y.; Park, D. S.; Yun, Y. S.; Han, J. W.; Yi, J. ChemSusChem 2014, 7, 2193-2201.

(35) Khatun, N.; Rini, E. G.; Shirage, P.; Rajput, P.; Jha, S. N.; Sen, S. Mater. Sci. Semicond. Process. 2016, 50, 7-13. 
(36) Zavahir, S.; Xiao, Q.; Sarina, S.; Zhao, J.; Bottle, S.; Wellard, M.; Jia, J.; Jing, L.; Huang, Y.; Blinco, J. P.; Wu, H.; Zhu, H.-Y. ACS Catal. 2016, 6, 3580-3588.

(37) Feng, S.; Li, W.; Shi, Q.; Li, Y.; Chen, J.; Ling, Y.; Asiri, A. M.; Zhao, D. Chem. Commun. 2014, 50, 329-331.

(38) Zhang, W.; Wang, Q.; Wu, H.; Wu, P.; He, M. Green Chem. 2014, 16, 4767-4774.

(39) Zhang, W.; Liu, T.; Wu, H.; Wu, P.; He, M. Chem. Commun. 2015, 51, 682-684.

(40) Wei, J.; Zhou, D.; Sun, Z.; Deng, Y.; Xia, Y.; Zhao, D. Adv. Funct. Mater. 2013, 23, 2322-2328.

(41) Zhang, R.; Tu, B.; Zhao, D. Chem. - Eur. J. 2010, 16, 99779981.

(42) Avansi, W.; Arenal, R.; de Mendonca, V. R.; Ribeiro, C.; Longo,

E. CrystEngComm 2014, 16, 5021-5027.

(43) Zhang, J.; Li, M.; Feng, Z.; Chen, J.; Li, C. J. Phys. Chem. B 2006, 110, 927-935.

(44) Su, J.; Zou, X.; Li, G.-D.; Jiang, Y.-M.; Cao, Y.; Zhao, J.; Chen, J.-S. Chem. Commun. 2013, 49, 8217-8219.

(45) Liu, H.; Wu, Y.; Zhang, J. ACS Appl. Mater. Interfaces 2011, 3, 1757-1764.

(46) Li, A.; Wang, Z.; Yin, H.; Wang, S.; Yan, P.; Huang, B.; Wang, X.; Li, R.; Zong, X.; Han, H.; Li, C. Chem. Sci. 2016, 7, 6076-6082.

(47) Pradhan, S.; Bartley, J. K.; Bethell, D.; Carley, A. F.; Conte, M.; Golunski, S.; House, M. P.; Jenkins, R. L.; Lloyd, R.; Hutchings, G. J. Nat. Chem. 2012, 4, 134-139.

(48) Gouma, P. I.; Mills, M. J. J. Am. Ceram. Soc. 2001, 84, 619-622.

(49) Luo, W.; Li, Y.; Dong, J.; Wei, J.; Xu, J.; Deng, Y.; Zhao, D. Angew. Chem., Int. Ed. 2013, 52, 10505-10510.

(50) Bulushev, D. A.; Rainone, F.; Kiwi-Minsker, L.; Renken, A. Langmuir 2001, 17, 5276-5282.

(51) Khan, M.; Song, Y. T.; Chen, N.; Cao, W. B. Mater. Chem. Phys. 2013, 142, 148-153.

(52) Luo, Z.; Poyraz, A. S.; Kuo, C.-H.; Miao, R.; Meng, Y.; Chen, S.Y.; Jiang, T.; Wenos, C.; Suib, S. L. Chem. Mater. 2015, 27, 6-17.

(53) Carrero, C. A.; Schloegl, R.; Wachs, I. E.; Schomaecker, R. ACS Catal. 2014, 4, 3357-3380.

(54) Zhao, W.; Zhong, Q. RSC Adv. 2014, 4, 5653-5659.

(55) Lee, K. J.; Kumar, P. A.; Maqbool, M. S.; Rao, K. N.; Song, K. H.; Ha, H. P. Appl. Catal., B 2013, 142-143, 705-717.

(56) Kang, M.; Park, E. D.; Kim, J. M.; Yie, J. E. Appl. Catal., A 2007, 327, 261-269.

(57) Nakka, L.; Molinari, J. E.; Wachs, I. E. J. Am. Chem. Soc. 2009, 131, 15544-15554.

(58) Song, H.; Jeong, T. G.; Moon, Y. H.; Chun, H. H.; Chung, K. Y.; Kim, H. S.; Cho, B. W.; Kim, Y. T. Sci. Rep. 2015, 4, 4350.

(59) Boningari, T.; Somogyvari, A.; Smimiotis, P. G. Ind. Eng. Chem. Res. 2017, 56, 5483-5494.

(60) Slot, T. K.; Eisenberg, D.; van Noordenne, D.; Jungbacker, P.; Rothenberg, G. Chem. - Eur. J. 2016, 22, 12307-12311.

(61) Chen, Y.-K.; Lin, Y.-F.; Peng, Z.-W.; Lin, J.-L. J. Phys. Chem. C 2010, 114, 17720-17727.

(62) Cassanas, G.; Morssli, M.; Fabrègue, E.; Bardet, L. J. Raman Spectrosc. 1991, 22, 409-413.

(63) Kaichev, V. V.; Chesalov, Y. A.; Saraev, A. A.; Klyushin, A. Y.; Knop-Gericke, A.; Andrushkevich, T. V.; Bukhtiyarov, V. I. J. Catal. 2016, 338, 82-93.

(64) Chieregato, A.; Bandinelli, C.; Concepción, P.; Soriano, M. D.; Puzzo, F.; Basile, F.; Cavani, F.; Nieto, J. M. L. ChemSusChem 2017, 10, 234-244.

(65) Wen, B.; Li, Y.; Chen, C.; Ma, W.; Zhao, J. Chem. - Eur. J. 2010, 16, 11859-11866.

(66) Garcia, A.; Yan, N.; Vincent, A.; Singh, A.; Hill, J. M.; Chuang,

K. T.; Luo, J.-L. J. Mater. Chem. A 2015, 3, 23973-23980.

(67) Gärtner, C. A.; van Veen, A. C.; Lercher, J. A. J. Am. Chem. Soc.

2014, 136, 12691-12701. 